\title{
Meningiomatosis in non-neurofibromatosis patient: how we dealt with 8 tumors
}

\begin{abstract}
Meningiomatosis (multiple meningioma) are defined by the presence of at least 2 simultaneous lesions present at different intracranial locations without an association with neurofibromatosis type 2 . It accounts for $1-10 \%$ of meningioma. it is usually common in females. It can occur with or without signs of neurofibromatosis. The primary goal of treatment is to remove the lesion causing sign and symptoms and to follow others. Surgery is the main treatment option as like solitary meningioma and the prognosis is usually very good. We will discuss here a case of 52 years female diagnosed as a case of multiple meningioma describe her clinical, radiological and histopathological features. We will also highlight the surgical managements and postoperative course.
\end{abstract}

Keywords: meningiomatosis, neurofibromatosis, meningioma

\author{
Volume 8 Issue 6 - 2018 \\ Bipin chaurasia,' Mohammad Hossain,' \\ Kanak Kanti Barua,' Rokibul Islam Rokib,' \\ Pulak Biswas,' Mithun Sardar,' Vijay \\ Raut,' Soumen Samadder,' Ranjit Kumar \\ Chaurasiya,' Dhiman Chowdhury,' Haradhon \\ Deb Nath,' Akhalaque Hossain Khan,' ATM \\ Mosharef Hossain, ' Ayub Ansari,' Nazmin \\ Ahmed Lopa,' Raushan Kumar Chaurasia ${ }^{2}$ \\ 'Department of neurosurgery, Bangabandhu sheikh mujib \\ medical university, Bangladesh \\ ${ }^{2}$ Bhawani hospital and research centre, Nepal
}

Correspondence: Bipin chaurasia, International hall, Dhaka university, shahbag, Dhaka, Bangladesh, Tel 00880I73253I039, Email trozexa@gmail.com

Received: July 27, 2018 | Published: December 29, 2018

\section{Introduction}

Meningiomas are the most common primary intracranial benign tumor. it's incidence is $13-26 \%$ and occur most commonly in females .It is a slow growing extra axial tumor and is usually a well circumscribed lesion. ${ }^{1-3}$ Meningiomatosis is defined as more than 2 meningioma occurring at same time in different locations without an association with neurofibromatosis type $2 .{ }^{4}$ Although meningiomas are common tumor, meningiomatosis is a rare entity encompassing $1-2 \%$ of all meningiomas cases., ${ }^{4,5}$ Multiple meningiomas occur frequently in association with neurofibromatosis type 2 but sporadic form is less common. ${ }^{6}$

\section{Case report}

A 52 years female non diabetic, non-hypertensive and menopause since 15 years presented to us with the complaint of headache, weakness in right side of body parts and sparse verbal output since 6 months. There was no family history of meningiomatosis or neurofibromatosis type 2. She had no history of prior irradiation, convulsions, loss of consciousness and altered bowel and bladder functions. General physical examinations of patients revealed no cutaneous stigmata of neurofibromatosis. Examinations of nervous system showed GCS 15 and hemiplegic gait. All cranial nerves examinations revealed normal findings except cranial nerve 11 where her visual acuity was 6/12 bilaterally. Funduscopic and visual field analysis revealed normal findings. She was not tested for NF2 mutations in blood.

CT scan revealed large well defined multiple rounded hyper dense mass with surrounding hypo density at left fronto- parietal region. Largest one was measuring about $5 \times 4 \mathrm{~cm}$. One of the lesion had multiple flecks of calcifications within it with hyperostosis of inner table adjacent to the lesion in frontal region. The lesion was causing mass effect evident by effacement of sulci, gyri and white mater on ipsilateral side. There was mild midline shift to the contralateral side. Post contrast images showed strong enhancement by lesions (Figure $1)$.

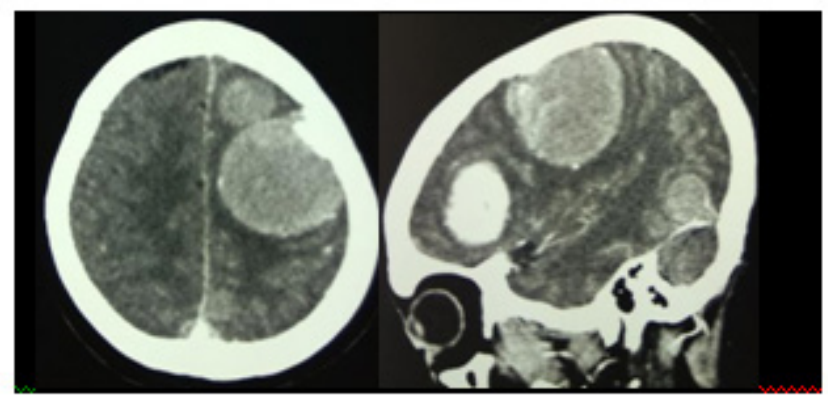

Figure I Post contrast images showing lesions.

MRI showed a large oval extra axial mass measuring $5.3 \times 5.0 \mathrm{~cm}$ was present over left parietal convexity. The lesion was hypo intense in T1W, hyper intense on T2W image and after IV contrast showed moderate homogenous enhancement. The mass was abutting on meningeal surface. Third and lateral ventricles were compressed due to mass with rightward shift of midline structure. Few others extra axial lesions of almost similar signal intensity and enhancement were noted over left front parietal region. The MRI features of lesions were highly suggestive of multiple meningioma (Figure 2). MRV of brain showed normal findings except the presence of left hypo plastic transverse sinus (Figure 3). MRI didn't showed any lesions like bilateral vestibular schwannoma in cerebello pontine angle consistent with neurofibromatosis type 2 .

Large fronto- parietal craniotomy was done. 4 tumors were removed at same time including the largest one. The hyperostotic parts of bone were drilled away and made flat. Duroplasty was achieved 
with $\mathrm{G}-$ Patch. Figure 4 shows Intraoperative images and 4 intact meningioma removed.

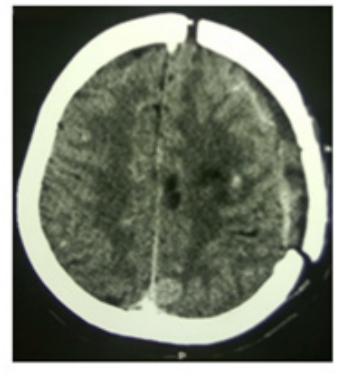

A)

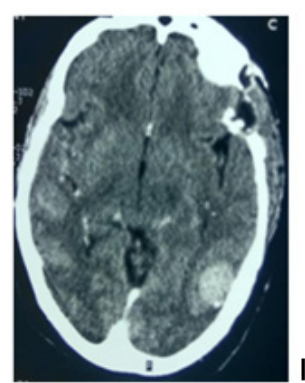

B)
Figure 2 Postoperative image showing big tumors were removed.

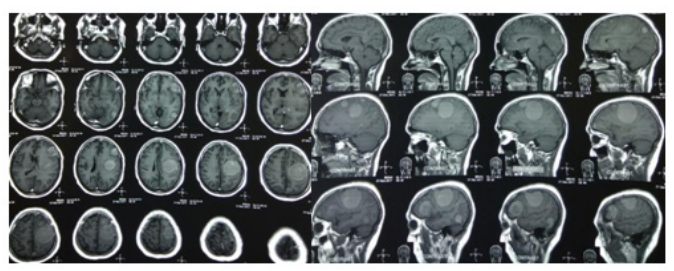

Figure 3 MRV of brain.

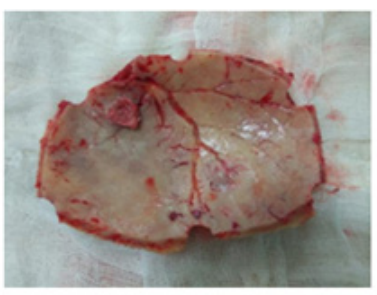

A)

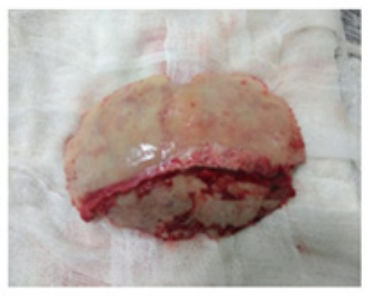

B)

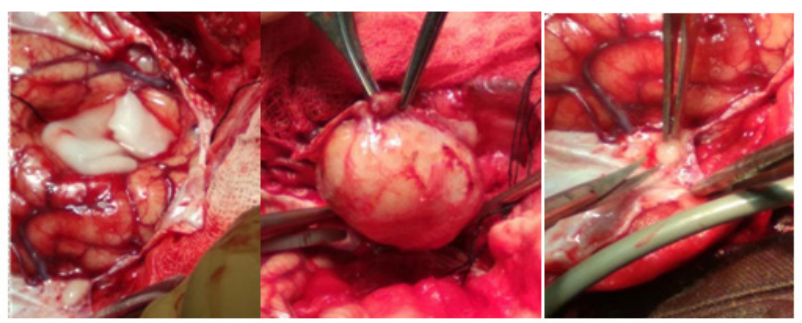

C)

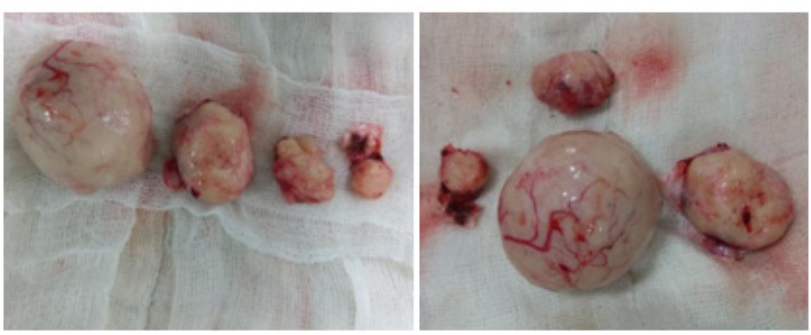

D)

Figure 4 Intraoperative images and 4 intact meningioma removed.
Histopathology revealed a neoplasm composed of oval to spindle cells arranged in fascicles and focal storiform which is consistent with fibrous type meningioma WHO grade 1 . We did immunohistochemistry analysis which showed Ki $67-1-2 \%$ of cells were positive. Progesterone receptors (PR) were also positive. After surgery she showed remarkable improvement from day 1 postop. The hemiparesis remarkably improved. The power of hemiparetric limb became 4 which was preoperatively 0 in right side. She became able to stand by her own in day 3 post Op (Figure 5). At the time of discharge her headache improved and was scheduled for follow up after 1 month. She was advised to take mifepristone tablet 100 $\mathrm{mg} \mathrm{BD}$, planned for repeat MRI after 6 months and follow up of remaining small meningioma .

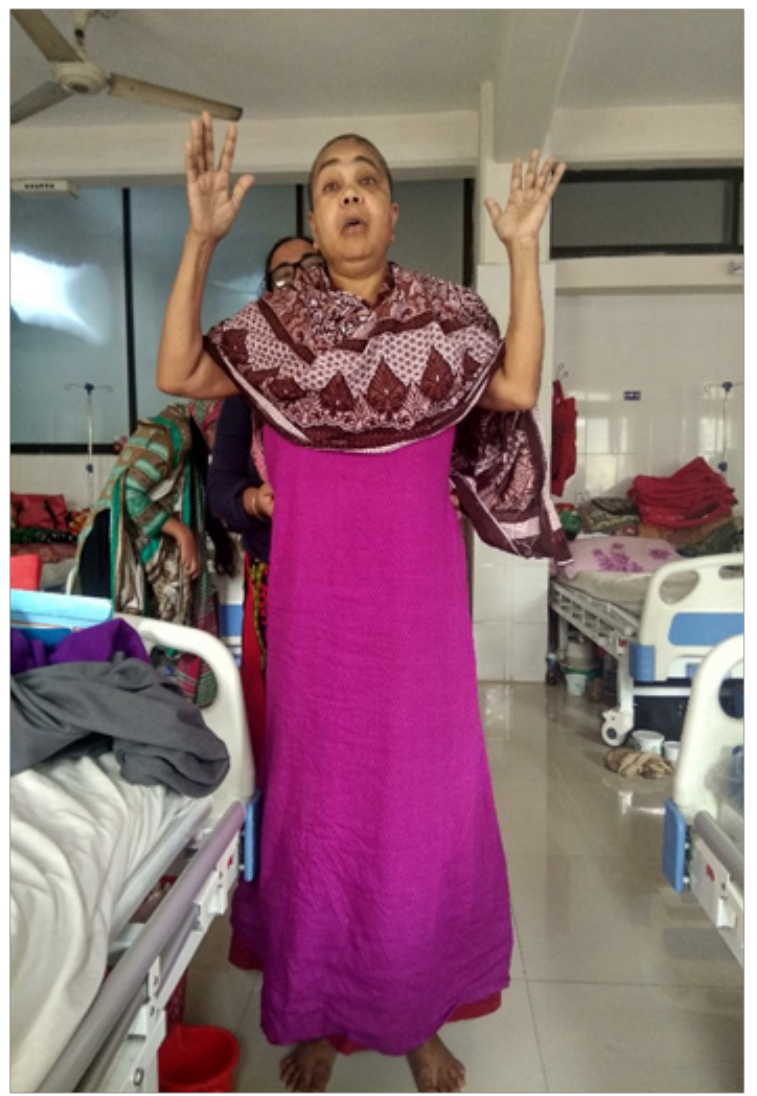

Figure 5 Result of patient after post Op.

\section{Discussion}

Meningioma is a benign tumor which arise from arachnoidal cap cells. It usually occurs in middle age group. There is female preponderance having male female ratio is 1:2. These are well circumscribed, slow growing lesions and are curable by surgery depending on the sites of its occurrence. ${ }^{7,8}$ The term multiple meningioma was given by Cushing and Eisenhardt and defined as equal to or more than 2 spatially separated synchronous or metachronous lesions which occurs in upto $10 \%$ of meningiomas. ${ }^{9-11}$

Most of meningiomas including multiple meningiomas occur sporadically .Multiple meningiomas are also associated with neurofibromatosis type $2 .{ }^{12}$ Some of the cases of multiple meningioma with numbers of tumor and their associations with neurofibromatosis have been shown in Table 1. 
Table I Showing some of the case of meningiomatosis.

\begin{tabular}{|c|c|c|c|}
\hline Author and year & Age/sex & No of meningioma & Associations with neurofibromatosis \\
\hline \multirow[t]{6}{*}{ Eljamel and foy ${ }^{10} / 1989$} & $38 / \mathrm{m}$ & 2 & no \\
\hline & $28 / f$ & 4 & \\
\hline & $61 / f$ & 3 & \\
\hline & $46 / f$ & 2 & \\
\hline & $57 / f$ & 2 & \\
\hline & $33 / f$ & 2 & \\
\hline Agrawal and mahapatra ${ }^{16} / 2005$ & $27 / f$ & 20 & No \\
\hline \multicolumn{4}{|l|}{ Ojo and fynn $6 / 2006$} \\
\hline & $57 / f$ & 2 & No \\
\hline & $49 / f$ & 2 & No \\
\hline & $51 / f$ & 2 & no \\
\hline Koech et al. ${ }^{4} / 2013$ & $75 / f$ & 2 & No \\
\hline Yudoyono et al." /2015 & $28 / \mathrm{m}$ & 2 & no \\
\hline Setia et al. ${ }^{9} / 2017$ & $33 / f$ & 14 & no \\
\hline Chaurasia et al /2018 (Our case) & $52 \mathrm{f}$ & 8 & no \\
\hline
\end{tabular}

There are two hypothesis which shows the development of multiple meningioma. The first one says that a single transforming events occur and the original clone of cells spread throughout the meninges in the formation of multiple clonally related tumors. The second hypothesis suggests the tumor arises independently which has been supported by the reported histological and cytogenetic difference between the multiple tumors from same patients ${ }^{13}$.

In total 10 cases of multiple meningioma has been described by Locatelli et al from 1977-1984 in a series of 227 intracranial meningioma. Among them all 10 cases were female, GalabetrzGonzdez reported 13 cases of multiple meningioma, all of them had no relationship with the neurofibromatosis. After the introduction of CT, Domenicucci et al. reported that the incidence of multiple meningioma has been rises from 0.58 to $4.5 \% .{ }^{9}$

A Arcos et al..$^{5}$ described 3 cases of multiple meningioma. None of the cases has any cutaneous stigmata of neurofibromatosis neither were any association with family history. ${ }^{5}$ Must of the cases of multiple meningioma occur in supratentorial convexity locations. They are usually benign and infratentorial location is very rare. ${ }^{14}$ In our case all the meningiomas were in supratentorial location. Some are in convexity and some are attached to falx. None of the meningioma was located in infratentorial locations.
Different histopathological subtypes and different grades have been described in multiple meningioma .The majority are benign and WHO grade $1 .^{4}$ The most common histological types reported in multiple meningiomas are psammomatous, fibrous, meningothelial, and transitional type. ${ }^{10,13-15}$ Our case histopathology reported as fibrous type WHO grade 1. There were no multiple histopathological subtypes and grading seen in our case.

Regarding the treatment, surgery is the main choice if the lesion is symptomatic, $>0.3 \mathrm{~cm}$ and in surgically accessible site. The prognosis is usually very good being its benign in nature. The prognosis doesn't differ from solitary benign meningioma. As the tumor grows very slowly the small tumors can be followed up every 6 months then 1 year if it is not symptomatic. ${ }^{4}$ Our case has 8 meningimas located in different locations. We removed 4 lesions in one setting. The remaining 4 were very small without causing any symptoms. So we decided to follow up after 6 months with repeat contrast MRI .The intraoperative findings revealed numerous small meningioma that were not visible in CT and MRI scan.so we concluded that there were perhaps more than 8 meningioma in that individuals.

\section{Conclusion}

Multiple meningiomas are common benign tumor occurring in multiple sites in same individual at same time. it is more common in 
females. Sometimes it is associated with neurofibromatosis. Surgery is the main stay of treatment for symptomatic meningioma. Prognosis is usually good and same like solitary cases. All the meningiomas at single sitting are difficult to remove due to its different locations. So proper planning is important to remove the one causing sign and symptoms and remaining small meningioms can be followed up.

\section{Acknowledgments}

None.

\section{Conflicts of interest}

The author declares no conflicts of interest.

\section{References}

1. Dowd CF, Halbach VV, Higashida RT. Meningiomas: the role of preoperative angiography and embolization. Neurosurgical focus. 2003;15(1):1-4.

2. Gasparetto EL, Leite CD, Lucato LT, et al. Intracranial meningiomas: magnetic resonance imaging findings in 78 cases. Arquivos de neuro-psiquiatria. 2007;65(3A):610-614.

3. Lin BJ, Chou KN, Kao HW, et al. Correlation between magnetic resonance imaging grading and pathological grading in meningioma. $J$ Neurosurg. 2014;121(5):1201-1208.

4. Koech F, Orege J, Ndiangui F, et al. Multiple intracranial meningiomas: a review of the literature and a case report. Case reports in surgery. 2013;2013:131962.

5. Arcos A, Serramito R, Santin JM, et al. Meningioangiomatosis: clinical-radiological features and surgical outcome. Neurocirugia 2010;21(6):461-466.
6. Ojo A, Fynn E. Multiple meningiomas. SA Journal of Radiology. 2006;10(2):21-3.

7. Commins DL, Atkinson RD, Burnett ME. Review of meningioma histopathology. Neurosurg Focus. 2007;23(4):E3

8. Setia V, Sachdeva D, Odugoudar S, et al. Rare case of multiple meningiomas in nonneurofibromatosis patient at unusual locations. Romanian Neurosurgery. 2017;31(2):240-243.

9. Eljamel MS, Foy PM. Multiple meningiomas and their relation to neurofibromatosis: Review of the literature and report of seven cases. Surg Neurol. 1989;32(2):131-136.

10. Yudoyono F, Sidabutar R, Arifin MZ, et al. Multiple meningiomas consisting of fibrous meningioma, transitional meningioma, and meningotheliomatous meningioma in one adult patient. Asian J Neurosurg. 2015;10(4):348.

11. Evans DG, Watson C, King A, et al. Multiple meningiomas: differential involvement of the NF2 gene in children and adults. J Med Genet. 2005;42(1):45-48.

12. Tsermoulas G, Turel MK, Wilcox JT, et al. Management of multiple meningiomas. J Neurosurg. 2017;128(5):1403-1407.

13. Terrier LM, François P. Multiple meningiomas. Neuro-Chirurgie. 2016;62(3):128-135.

14. Alam Shamsul, Bipin Kumar Chaurasia, Narendra Shalike, et al. Surgical management of clinoidal meningiomas: 10 cases analysis. Neuroimmunology and Neuroinflammation. 2018;5:21.

15. Agrawal D, Mahapatra A. Multiple intracranial meningiomas do not imply neurofibromatosis. Neurology India. 2005;53(2):255. 